\title{
An Agile Knowledge Sharing Platform for Risk Management in SMEs
}

\author{
Lucas Peter Brasen, Oliver Fuglsang Grooss, Rasmus Tange Præstegaard, Pernille Clausen \\ and Torben Tambo \\ Department of Business Development and Technology, Herning, Denmark \\ brasen1995@gmail.com \\ fuglsang.2@hotmail.com \\ rasm5731@gmail.com \\ pc@btech.au.dk \\ torbento@btech.au.dk \\ DOI: $10.34190 /$ KM.19.172
}

Abstract: Structuring, distributing, and managing knowledge (KM) can be especially challenging in Small and Midsized Enterprises (SMEs) with limited manpower and technology resources. When maintaining updated, relevant, and actionable knowledge on risk management (RM) in a company, it is critical to enact proper KM design and approaches fitting the limited capabilities of the SME. This paper presents and analyses a conceptual approach for SMEs to work with RM in a simple workshop setting that helps employees and management to identify, track, and respond to risks dynamically. The design of this research is based on creation of a risk matrix and a risk action board with six variants of parameters set from ISO 31000 and Failure Mode Effect Analysis (FMEA). The boards are physical in A0 size and highly coloured. The boards are developed from a pre-screening and requirement elicitation process in six different companies in three different industries with observations and selected interviews as the basic methods of data collection. This paper's originality lies in the conveyance of a highly visible and dynamic visualization of current knowledge that addresses the full organization on a daily basis. The introduction of RM as a cornerstone in the fundamental shop floor KM processes of daily communication is proving a valuable tool in both KM, RM, and employee engagement. The main research implication of this paper is that it provides a better and more detailed understanding of the otherwise abstract RM concepts and their application on the shop floor level. RM is assumed to reach a more communicable and inclusive format. Long term impacts still remain to be investigated.

Keywords: knowledge management, risk management, FMEA, small and midsize enterprise, shop floor communication

\section{Introduction}

The ability for companies to collect, present and utilize their pool of knowledge assets is essential in proper management. One critical dimension of knowledge management (KM) is to enrich those key elements of knowledge that can contribute to avoidance of risk in decision-making (Marie, et al., 2018). Risk Management (RM) is a management discipline highly reliant on well organised processes within KM. While RM and KM are relatively well established in larger organisations, small and medium-sized enterprises (SMEs) tend to mismanage or ignore their risk and only respond reactively to emerging, obvious, or foreseeable risks (Chiweshe and Naude, 2017). From the KM literature it is given that knowledge represents a life-cycle with KM addressing knowledge creation, knowledge storage, knowledge retrieval, knowledge transfer, knowledge application (Alavi and Leidner, 2001; Ruggles, 1998), and lastly cleaning up, removal, and "right to be forgotten". In the context of RM, two parallel KM agendas must be investigated. One agenda is to scrutinize explicit knowledge in its lifecycle and ensure proper interaction between risk and knowledge perspectives. Another agenda of KM is more human, inter-human, and organisational with issues of elicitation, vocalisation, culture and environment along with a more strategic aspect of knowledge (Davenport et al., 1998; Earl, 2001; Gold, et al., 2001). Departing from the perspectives of RM as being deeply related to learning in a situational context, agility is central to this study (Nonaka and von Krogh, 2009), and it is specifically related to the object of the transition (Sanchez and Mahoney, 1996). The KM dimension is a matter of the relationship between the collectivist and individualist perspectives in KM (von Krogh, 2009).

ISO states: "risk is an effect of uncertainty on objectives" (ISO, 2018). The ISO31000 standard describes an effect as; "a deviation from the expected. It can be positive, negative or both, and can address, create or result in opportunities and threats." (ISO, 2018). Risk is usually expressed in four terms (Tranchard, 2018). (1) Risk sources are elements having the potential to give rise to risk. (2) Potential events are occurrences or changes in a particular set of circumstances. (3) Consequences are the outcome of an event which affects objectives. (4) Likelihood is the chance of incidence (ISO, 2018; ISO, 2016). 


\section{Lucas Peter Brasen et al.}

The European Union defines an SME as an enterprise with a staff headcount less than 250 or a turnover less than EUR 50 (EU, 2003 SMEs play an important role, and their failure related on insufficient RM has consequences (Falkner and Hiebl, 2015; Islam and Tedford, 2012).

In a systematic review of RM in SMEs, a number of potential research questions with limited coverage in existing literature were identified (Falkner and Hiebl, 2015). KM and RM in SMEs were further limited. Academically, it is interesting to use SMEs in lieu of more fundamental, ad-hoc and emergent KM processes. It is also interesting to sustain a process of professionalization in SMEs by using academic methods to develop and adapt tools of relevance such as KM and RM. The impact of improved RM in SMEs is potentially sizable. A survey of 196 Danish SMEs concluded that $90 \%$ of the responding SMEs have discussed risks in management or board meetings within the last year, while only $20 \%$ have written plans for how to respond to a crisis resulting from known or unknown risks (Torvits and Goosmann, 2016). This shows that a majority of the companies in Denmark do not work with risk and, according to Dansk Statistik, $99 \%$ of the companies in Denmark are SMEs (Jensen, Moltrup-Nielsen and Nielsen, 2016). The research question for this paper is "how to design and create an experimental tool for improving RM in SMEs by specific use of KM-models inspired mainly for agile methods"? In this paper, an experimental tool was tested on a small set of companies. The tool is expected to be used much wider in order to deepen our understanding of knowledge and risk by adding digital elements of the tool and establishing a knowledge base for further research.

\section{Literature review}

\subsection{RM from a knowledge perspective}

This paper follows RM as defined in the ISO 31000 standard (ISO, 2018). ISO 31000 differs from other familiar ISO standards, like ISO 9001 and ISO 14001, by being less normative. With ISO 31000, businesses will choose which guidelines to apply in their company based on what they find suitable in their context (Tranchard, 2018).

ISO 9001 and ISO 14001 mandate implementation of RM to implement risk-based thinking over preventive actions (de Oliveira et al., 2017). ISO31000 guides the company through a set of activities for identifying and treating risks while monitoring their current situations and conferring with relevant internal and external stakeholders (Figure 1) (de Oliveira et al., 2017). The overall goal is to establish a RM culture where employees and stakeholders are vigilant to risk and bring attention to both positive opportunities and negative consequences (Tranchard, 2018). Even though it is a framework, it is not intended to be a prescribed management system (Dali and Lajtha, 2012). ISO 31000 is considered largely to be a connection to the following top level processes:

- Communication and consultation.

- Establishment of context.

- Risk Identification (ISO, 2018).

Risk Analysis: Understanding the nature of the risks identified and their characteristics including the relevance of a risk based on uncertainties, risk sources, occurrences, consequences, effectiveness, and complexity.

Risk Evaluation: Comparing the results of the analysed risks with the previously established risk criteria to determine where to engage.

Risk mitigation is a process for selecting and implementing possible solutions. This process is iterative, learningoriented and involves formulating and selecting action options, planning and action implementation, and action assessment:

- Avoiding the risk - preventing it from arising.

- Taking or increasing the risk to pursue an opportunity

- Reducing the or enhancing the likelihood of the risk.

- Changing the consequences

- Transferring the risk

- Retaining the risk. 
Knowledge perspectives would add extensive use of existing KM resources, aligning RM and KM systems, mapping lessons learned repositories, extending or augmenting KM where necessary, establishing appropriate communication channels, and setting policies for employee inclusion and active roles (Marie et al., 2018).

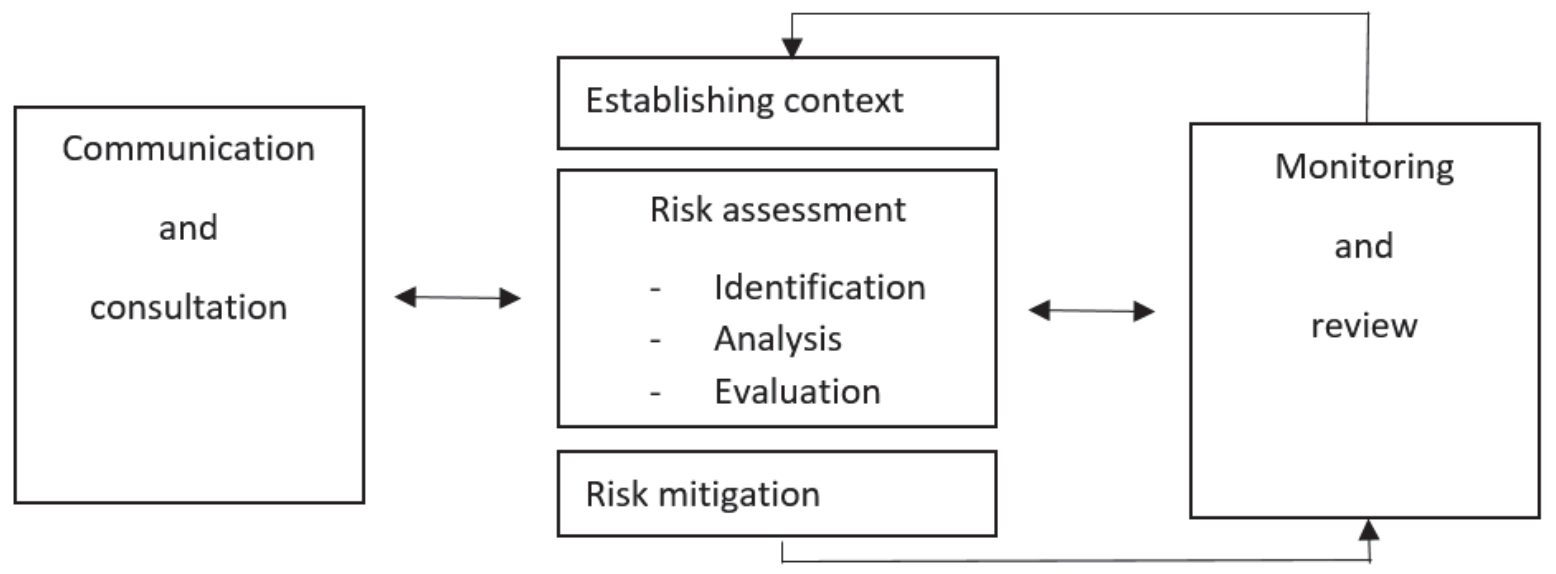

Figure 1: The ISO 31000 process

\subsection{Agile RM}

With agile practices in projects becoming more common and reflecting on projects as learning processes (especially SECI) (Nonaka and von Krogh, 2009), Moran (2016) presents RM techniques based on agile ways of working (Moran, 2016). Risk should be identified, assessed, treated and monitored on an iterative basis during a project. According to Moran, an agile RM approach could have the following steps:

- 1. Risk Identification and Assessment; a what-why brainstorm approach to identify potential risks. The assessment includes determining the relative risk exposure and a risk score.

- 2. Risk Treatment; a risk response (avoid, accept, exploit, etc.) is determined based on the assessment. The risk is visualized on a board

- 3. Risk Monitoring; the RM effort can be monitored using a Risk Burn-down chart, visualizing the progress (Moran, 2016).

$\mathrm{KM}$ is the foundation of the RM processes in respect to collective learning and inclusion of individual knowledge positions.

\subsection{FMEA - Failure Mode and Effect Analysis}

There are a number of risk assessment techniques available, but one of the more traditional is Failure Mode and Effect Analysis (FMEA) (Tavakolan and Mohammadi, 2018). In the traditional FMEA, several potential failure modes are identified in a scoring system from 1 to 10 based on the following: severity, occurrence rate, and detection rate. A Risk Priority Number (RPN) is calculated as the product of these three scores. The result is a prioritized list of potential failure modes (Kluse, 2017). FMEA is used to approach risk in both product design and company processes as well as the functionality of systems, see Table 1 (Krasaephol and Chutima, 2018).

Table 1: Process-FMEA table

\begin{tabular}{|l|l|l|l|c|c|c|}
\hline No. & Sub-Process & Potential Failure Modes & Severity & Occurrence & Detection & RPN \\
\hline 1 & \multirow{2}{*}{ Sub-process 1 } & Failure mode 1 & S-score & O-score & D-score & RPN \\
\cline { 3 - 7 } & & Failure mode 2 & S-score & O-score & D-score & RPN \\
\hline 2 & Sub-process 2 & Failure mode 1 & S-score & O-score & D-Score & RPN \\
\hline
\end{tabular}

Kluse (2017) investigated factors affecting execution and implementation of FMEA; when responding to "can add value, however, most added that it was too tedious, subjective, a paper exercise, created only to satisfy a requirement". Oguz et al. (2018) propose an extension to FMEA named Human Design Approach (HDA) 


\section{Lucas Peter Brasen et al.}

combining FMEA with HRA (Human Reliability Analysis) that "provides an estimate of the probability of failure due to human interaction by combining both the probability and the degree of contact". HDA is for designing reliable products, but it is also relevant to explore the human risk factor in the context of SMEs.

There are scenarios instead of failure modes. Kmenta \& Ishii describes FMEA as having three major phases: identify failures, prioritize failures, and reduce risk. Kmenta \& Ishii (2000) present two improvement suggestions:

- Organize the FMEA around failure scenarios rather than failure modes.

- Evaluate risk using probability and cost.

FMEA is narrowly based on corporate KM instruments to map, model, and analyse the product in focus, especially using lessons learned from similar or analogue projects (Alavi and Leidner, 2001). The Risk Matrix is defined by Duijm (2015) as a two-dimensional grid whereupon a risk can be plotted in terms of likelihood to happen and the consequence of the risk happening. The colouring and numbering (RPN) of the plots in the Risk Matrix is portrayed as a single dimension supporting the mapping of risk as effective and significant in influencing decision making regarding tolerability and prioritization (Duijm, 2015).

\subsection{Implementing RM in SMEs using workshops}

The literature on the implementation of RM in SMEs is limited. However, Ekwere (2016) describes the following four elements needed to sustain the RM process in small businesses:

- 1. Risk and opportunity

- 2. RM application system

- 3. Commitment

Fraser \& Simkins describes eight internal challenges in RM: corporate culture, board of directors' knowledge, over-complexity, premature training, over-assessing risk, no timeframe, lack of meaningfulness, and overlooking RM as change management. In their paper, Fraser \& Simkins also present a solution for implementing RM with 26 basic techniques, and they highlight the importance of champions in the company that can engage other employees in the RM effort (Fraser and Simkins, 2016).

\subsection{Implementing RM in SMEs}

Fraser and Simkins (2016) suggested RM workshops as a technique. Mikes and Kaplan (2012) present a case where a Canadian company successfully conducts several risk workshops yearly. The prioritization is done anonymously and is based on three factors: impact, likelihood, and strength of existing controls. The workshops end with a consensus on the importance of the risk and a recommended action plan. A similar involvement of employees is seen in a corporate foresight case by Cisco (Boe-Lillegraven and Monterde, 2015). Cisco created the opportunity for employees to contribute with inputs for different market opportunities and to act as "scouts" (Boe-Lillegraven and Monterde, 2015). Comparatively, there are RM techniques from the five steps of the Project Management Institute (PMI) approach to RM. Tavakolan and Mohammadi (2018) list workshops as the only technique that could encompass all five steps: planning, identification, analysis, response, and monitoring. In comparison, FMEA is only listed as being useful for identification, analysis, and response.

\section{Method}

This paper is based on a qualitative, socially-inspired, interpretivist case-based methodology. The paper is dichotomous in following a line of company studies of KM-based RM processes and creating a tool for improving collective knowledge creation and visualisation (generic) in the area of RM and FMEA as (specific) constructs. To conduct a creative concept development, several assumptions for the RM needs of SMEs were defined, based primarily on case and literature studies. The developed concept is fundamentally based on the ISO 31000 process, KM, and FMEA. To test the validity of these assumptions, an approach of rescoping, combining, and modifying existing tools and methods was chosen, rather than building something completely from scratch. Testing and verifying is outside the scope of this paper but is essential in future work. The creative approach consists of elements of design science research (Tambo, 2018) and classical KM (Earl, 2001; Nonaka and von Krogh, 2009). To verify and triangulate the theoretical position of the complexities of RM in SMEs, an empirical study was conducted on six Danish SMEs. The study was performed as qualitative case studies relying on semistructured interviews. The SMEs were selected based on the matrix in Table 2. 
Table 2: Case companies, segmented

\begin{tabular}{|c|c|c|c|}
\hline & $\begin{array}{c}\text { Category 1 } \\
\text { (Projects) }\end{array}$ & $\begin{array}{c}\text { Category 2 } \\
\text { (Simple mass production) }\end{array}$ & $\begin{array}{c}\text { Category 3 } \\
\text { (Complex batch production) }\end{array}$ \\
\hline $\begin{array}{c}\text { Smaller SME's (A) } \\
(50-100 \text { employees) }\end{array}$ & Heat Pumps & Tarpaulins & Craft brewery \\
\hline $\begin{array}{c}\text { Larger SME's (B) } \\
(200-250 \text { employees) }\end{array}$ & Construction & Carpets & Metal Processing \\
\hline
\end{tabular}

\section{Empirical work}

Category 1, project-based organisations: Case $1 \mathrm{~A}$ did not work with RM at all. It is not a part of their daily operations, and when the company was asked why they did not work with it, the answer was simply: "I actually don't know; we have never worked with it before and have therefore not considered it." Even though the Case $1 \mathrm{~A}$ company does not work with RM, they implied that they probably should do it. In Case 1B, RM was used on regular basis. Short whiteboard-meetings were conducted every other week to discuss the last two weeks and to look at the next 14 days of activities and what risks may arise, from these. By approaching it from a relaxed and practical angle, they have determined that risk assessment sheets and thorough calculations of risk factors are obsolete practices in their company.

Category 2, simple mass production: In the cases $2 \mathrm{~A}$ and $2 \mathrm{~B}$, significant differences showed up. In Case 2A, RM is considered irrelevant because the company mass produces their product. The company has few RM activities in finance and safety. In Case 2B, a much larger manufacturer of a complexity-similar product, the level of RM is very polarized. At this company, RM is used in their everyday operations as a part of their ISO 9001:2015. The newer certification demands a certain level of RM, which was previously known as "Preventive Actions".

Category 3, complex batch production: Cases, 3A and 3B are polarized. Case 3A involves a small brewery where RM was neglected. The company disregarded RM as being irrelevant because their production batches were small and handcrafted. The Case 3B company, a significant counterpart to Case 3A, had a completely different approach to RM. As in case 2B, RM had been introduced in connection with ISO 9001:2015. However, the main demands for RM arose as the company had to become IATF-certified because of a demand from a German automotive customer.

Neither of the smaller A-cases uses RM in their daily work, because they apparently have not yet seen the need for it. The major B-cases all apply some sort of RM - most of them in relation to ISO 9001:2015. This implies that companies are mainly focused on RM in connection with quality management - not mentioning RM on a structural level or as a broader governance regime.

\section{Proposed concept}

\subsection{Proposed framework}

The workshop framework is constructed around the three fundamental FMEA phases (identify, prioritize, and reduce) based on elements from ISO 31000:2018. The framework merges the iterative approach from Agile RM and KM with the use of RM Workshops. The subsequent model elements are derived from the academic literature surrounding ISO31000 with emphasis on the KM perspectives of individual and collective learning and knowledge creation. See Figure 2.

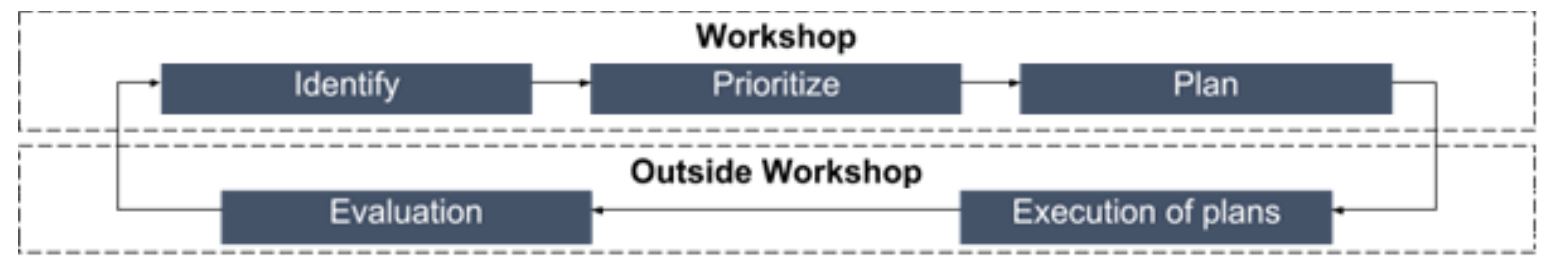

Figure 2: The proposed framework for RM workshops in SMEs 


\subsection{Workshop process}

The RM Workshop is a conceptual process on top of the proposed framework. Based on the literature review and the empirical findings, four precursory assumptions have been developed.

- 1 . The approach should encourage cross-organizational collaboration and visibility, while not requiring any digital tools like documents, spreadsheets or more specialized software from the KM processes of the company.

- 2. The approach should encompass most of the main elements from the ISO31000:2018 process.

- $\quad 3$. The approach should work with different ambition or detail levels, while being broad enough to apply to all the risk types identified.

- $\quad$ 4. The approach should be very simple and require few resources, so that it is possible to be implemented as a monthly or at least quarterly activity in SMEs.

This proposed process is composed of three phases, identify, prioritize and reduce, from the framework with each having an A0 physical poster for the "shop floor". Each board represents elements of ISO 31000 and should be used in a chronological order, see Table 3.

Table 3: Proposed three boards with activities and inspiration source

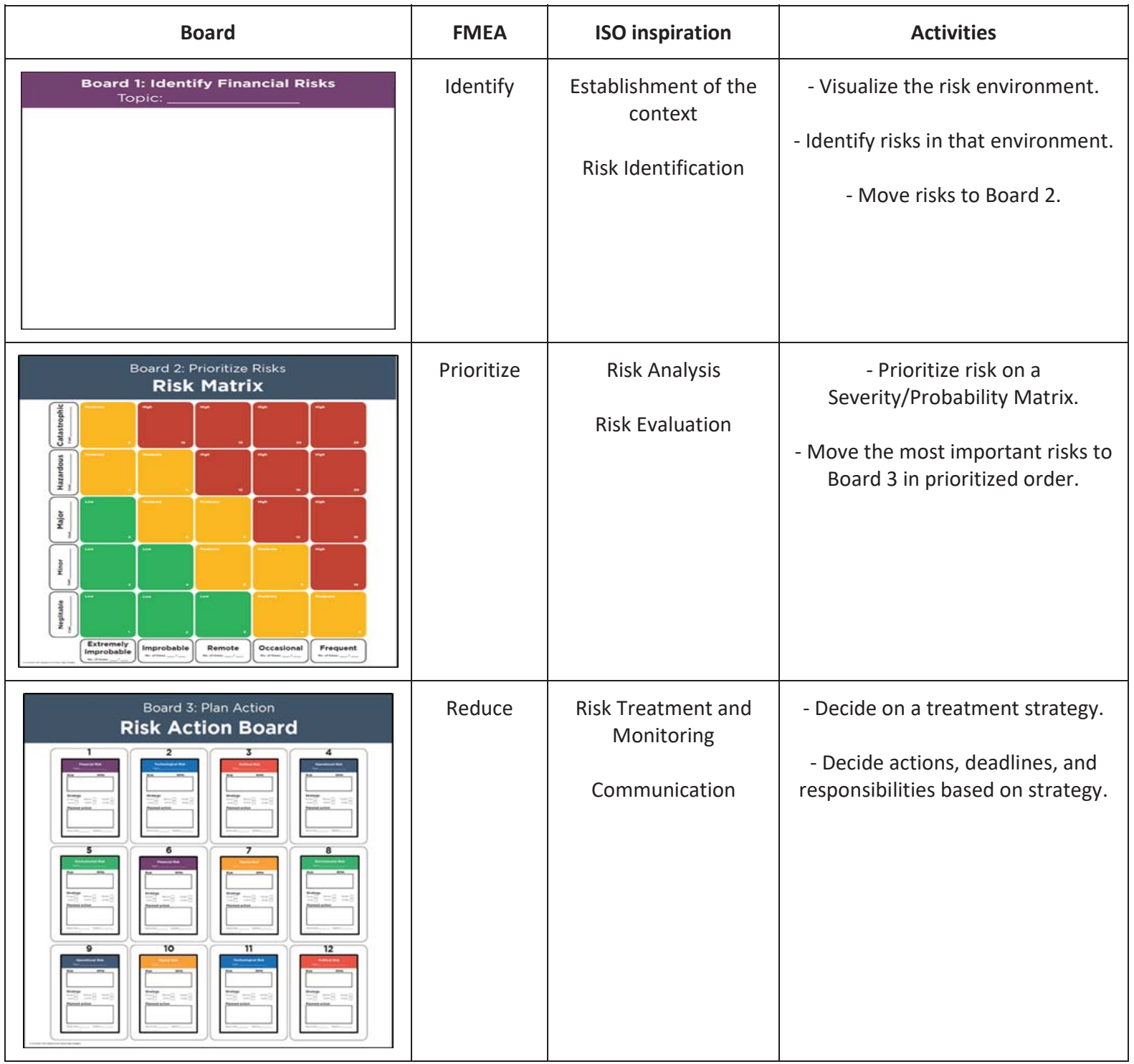




\section{Board 1 - Identify Risk}

The first phase of the workshop is centred around the initially blank Board 1. The first task is to establish the focus for the workshop by identifying a Risk Category (for example operational) and hereafter the Topic (for example quality Issues or workplace safety). Risk variety is picked. One taxonomy of risk variety is suggested by Chiweshe and Naude (2017): operational, market, technological, financial, political, and environmental Risk.

This provides flexibility for identifying potential risks in a given area of interest. Setting a specific topic is important for scoping the process (ISO, 2018). The alternation of the FMEA-approach is a result of the criticism of the original FMEA-approach and the inclusion of Failure Scenarios in contrast to Failure Modes presented in the literature review. This could be visualization like pictures of process and products, project plans, calendars, supply chain, production floor layout. These visual aids are expected to help the participants in identifying risk. The identified risk is posted on the board using post-it notes. When the topic is deemed sufficiently covered, the workshop continues the next phase and physically to Board 2.

\section{Board 2 - Prioritize Risk}

The second phase of the workshop is centred on prioritizing the identified risks from the previous board. The board for this phase uses a modified risk matrix, which allows for prioritizing the risk on two parameters, severity and probability (Duijm, 2015). To accommodate the fact that SMEs vary in sizes and risk tolerances, an element of customization has been added. The board allows the SME to input their own definitions for the five levels of both severity and probability. When the definitions are agreed upon, then the identified risks are discussed one by one and placed on the board. The placement on the board equivalates a Risk Priority Number (RPN) that is then assigned to that risk. The RPN score indicates which risks the company should focus on. The colouring and naming of the $5 \times 5$ grid are inspired by Duijm and the ISO 31000 - A Practical Guide for SMEs (Duijm, 2015; ISO, 2016). However, the assigning of grid names and colours are merely a suggestion rather than a conclusion, and this should be tested before a final decision is made.

\section{Board 3 - Reduce Risk}

The last phase of the workshop is centred on acting on and monitoring the most significant risks. The 12 risks with the highest RPN from Board 2 are transferred from a post-it note to an A5-sized card: a proposed RM Card (RMC). The RMC should be filled out with information on Risk Category, Topic, Identified Risk, RPN, Strategy, Planned Action, Responsibility, and Deadline. The 12 RMCs are placed in prioritized order on Board 3 . Figure 3 shows a proposed RMC.
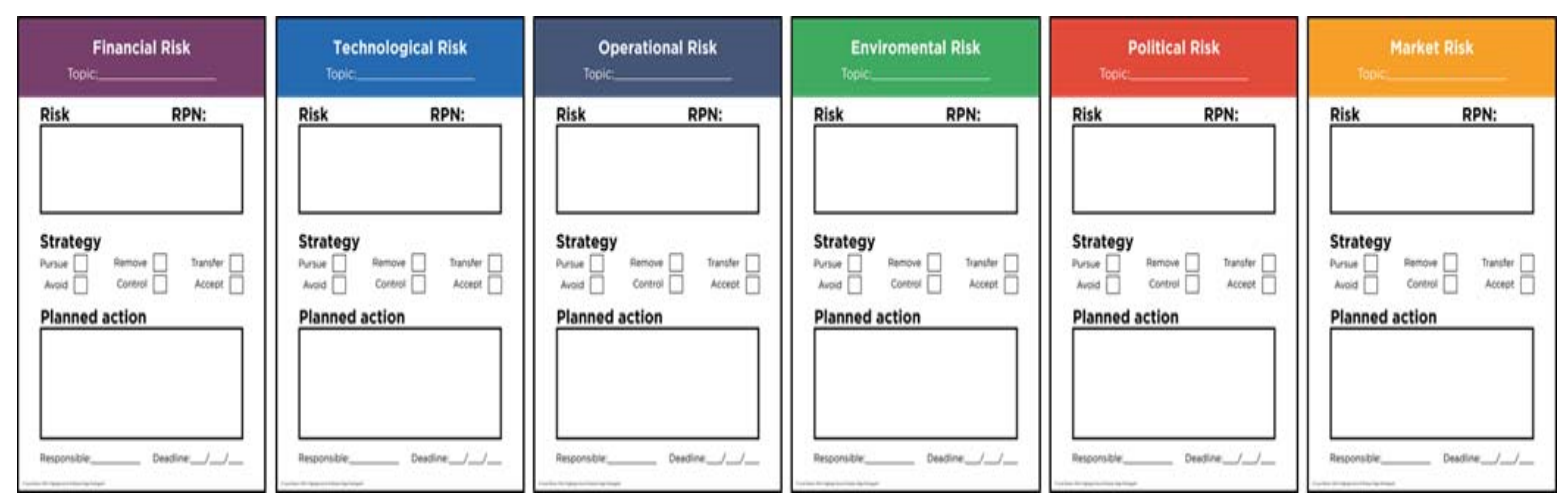

Figure 3: RM card for each risk category

The strategy is based on how the company decides to respond to the given risk. The RMC proposes six strategies: avoid, pursue, remove, share, control, and accept. The 'responsible' field is for designating an employee to have the responsibility for management of the given risk within a deadline.

When the RMC is filled out and placed on Board 3, the workshop is done. A date for the next workshop may be set, and the time in between is dedicated to working on the selected risk. Board 3 should be placed in a physical location where it can also work as a platform for monitoring. It's critical that the result of these workshops is not hidden away but rather presented as a constant reminder of the RM effort and commitment. 


\section{Lucas Peter Brasen et al.}

\section{Discussion and conclusion}

This study set out to create a tool for helping SMEs establish a clearer, more explicit and systems-based RM practice. The tool is based on KM principles. The motivation of this study is the recognized RM awareness among SMEs contrasted with the low level of action in documentation, systems, processes, and explicitness in RM. An additional motivation is a systematic use of academic principles and theories for improving industrial practices and assessing the feasibility and impact of such a motivation.

The RM tool uses principles from ISO 31000 and FMEA. The tool consists of three visual elements and a guiding process. The visual elements are the boards for identification, prioritisation and reduction made in $\mathrm{AO}$ format for display in area of high traffic, typically around the entrance to a factory hall. The RM tool is based on KM principles, primarily agile principles as set out in learning processes (Nonaka and von Krogh, 2009) such as those seen in Scrum. The three boards work as the team's collective social knowledge platform being qualified by iterative processes on daily and weekly basis. The iterations are on a team-basis but also on an individual basis; individuals are encouraged to contribute to as well as learn from the boards.

Three assumptions are the foundation for this study. The first assumption was that the process should be as flexible as possible in order to be applicable to all types of risk within most industries. This poses the question of whether the proposed concept may become too vague in its attempt to cover all aspects of RM in one workshop process. The second assumption was that the process should be resource-light and not require heavy documentation, training, and calculation to get started and keep going. Whether the proposed concept meets this assumption will be measured by whether SMEs will be willing to implement and maintain the approach over time. The last assumption was the need for the process to include all seven elements of ISO 31000 to ensure full coverage of RM.

This paper proposes the RM Workshop Process that was developed to test these assumptions. It is a concept for implementing RM strategies in resource-constrained SMEs. The conceptual workshop is intended to facilitate a focused RM process that helps the SME in the journey from realizing they have a risk to making a conscious decision on how to act upon the risk. KM elements are prevalent, as RM is seen as a specialisation of the general KM "framework" of the company. This is valid in extracting knowledge for performing the RM process and feeding back new knowledge to the KM system. This is also valid in the collective-individual knowledge creation design inspired with agile methods and agile RM. An academic implication for KM is to see KM used in critical specialisations in congruent contexts such as its use here in RM. This calls for KM to have an open "interface" to such congruent processes no matter if the KM is predominantly manual or digital. Furthermore, the implication is that process governance systems, such as RM, must identify and positively interact with core elements of KM to obtain optimal relevance and thereby have a chance to be positively embraced in the organisation.

Further work in this study relates to short and long term testing of the RM tool and workshop in diverse industries to assure validity. Industries that already have accepted this are within mechanical assembly, building components, logistics, and consumer products. This will be a journey of continuous improvement based on the feedback and observation from the real-life implementation in different SME sizes and industries. Future work will bring new knowledge on feasibility in the context of SMEs. This is still an area of research with a significant number of unanswered questions and the potential to make an important societal difference in the longevity of SMEs.

\section{References}

Alavi, M. and Leidner, D.E. (2001), “Knowledge management and knowledge management systems: Conceptual foundations and research issues", MIS quarterly, pp.107-136.

Boe-Lillegraven, S. and Monterde, S. (2015) "Exploring the cognitive value of technology foresight", Technological Forecasting and Social Change, Vol. 101, pp. 62-82.

Chiweshe, N. and Naude, M. (2017) "A proposed operational risk management framework for small and medium enterprises", South African Journal of Economic and Management Sciences, pp. 1-10.

Dali, A. and Lajtha, C. (2012) "ISO 31000 Risk Management- 'The Gold Standard'”, Edpacs, Vol. 45, No. 5, pp. 1-8.

Davenport, T.H., De Long, D.W. and Beers, M.C. (1998), "Successful knowledge management projects". Sloan management review, Vol. 39, No. 2, pp.43-57.

Duijm, N. J. (2015) "Recommendations on the use and design of risk matrices", Safety Science, Vol. 76, pp. 21-31.

Earl, M. (2001) "Knowledge management strategies", Journal of management information systems, Vol. 18, No. 1, pp.215233. 


\section{Lucas Peter Brasen et al.}

Ekwere, N. (2016) "Framework of Effective Risk Management in Small and Medium Enterprises", Bina Ekonomi, 20(1), pp. 23-44.

EU (2003) What is an SME? Available at: http://ec.europa.eu/growth/smes/business-friendly-environment/smedefinition en (Accessed: 9 December 2018).

Falkner, E. M. and Hiebl, M. R. W. (2015) "Risk management in SMEs: a systematic review of available evidence", Journal of Risk Finance, Vol. 16, No. 2, pp. 122-144.

Fraser, J. R. S. and Simkins, B. J. (2016) "The challenges of and solutions for implementing enterprise risk management", Business Horizons, Vol. 59, No. 6, pp. 689-698.

Gold, A.H., Malhotra, A. and Segars, A.H. (2001), "Knowledge management: An organizational capabilities perspective", Journal of management information systems, Vol. 18, No. 1, pp.185-214.

Islam, A. and Tedford, D. (2012) "Risk determinants of small and medium-sized manufacturing enterprises (SMEs)", Journal of Industrial Engineering International, Vol. 8, No. 1, pp. 1-13.

ISO (2016) ISO 31000 Risk Management - A Practical Guide for SMEs.

ISO (2018) "ISO 31000 Risk management - Guidelines", 2018.

Jensen, A., Moltrup-Nielsen, J. and Nielsen, P. (2016) "Hvornår er små virksomheder små?" Available at: http://www.dst.dk/Site/Dst/Udgivelser/nyt/GetAnalyse.aspx?cid=27867.

Kluse, C. (2017) "Failure Modes and Effects Analysis (FMEA)", The journal of Management and Engineering Integration, Vol. 10, No. 1.

Kmenta, S. and Ishii, K. (2000) "Scenario-Based FMEA a Life Cycle Cost Perspective", ASME Design Engineering Technical Conferences, pp. 1-11.

Krasaephol, S. and Chutima, P. (2018) "Quality control process improvement of flexible printed circuit board by FMEA", IOP Conference Series, Vol. 311, No. 1, pp. 1-8.

Marie, I., Sugiarto, D., Surjasa, D., and Witonohadi, A. (2018) "Knowledge management system for risk mitigation in supply chain uncertainty", IOP Conference Series: Earth and Environmental Science, Vol. 106, No. 1, pp. 12-18.

Mikes, A. and Kaplan, R. (2012) "Managing Risks: A New Framework", HBR, pp. 1-18.

Moran, A. (2016) "The Financial Management of Agile Projects", Itnow, Vol. 58, No. 3, pp. 60-61.

Nonaka, I., \& Von Krogh, G. (2009) "Perspective-Tacit knowledge and knowledge conversion: Controversy and advancement", Organization science, Vol. 20, No. 3, pp. 635-652.

Oguz, E., Kubicek, M. and Clelland, D. (2018) "Failure modes and criticality analysis of the preliminary design phase", Reliability Engineering and System Safety, Vol. 178, pp. 247-254.

de Oliveira, U. R. et al. (2017) "The ISO 31000 standard in supply chain risk management", Journal of Cleaner Production, 151, pp. 616-633.

Ruggles, R. (1998), "The state of the notion: knowledge management in practice", California management review, Vol. 40, No. 3, pp.80-89.

Sanchez, R. and Mahoney, J.T. (1996) "Modularity, flexibility, and knowledge management in product and organization design". Strategic management journal, Vol. 17, pp.63-76.

Tambo, T. (2018), "Enlightened Designers from the Dark”, Scandinavian Journal of Information Systems, Vol. 30, No. 2, pp. 63-68.

Tavakolan, M. and Mohammadi, A. (2018) "Risk management workshop application", International Journal of Construction Management, Vol. 18, No. 3, pp. 260-274.

Torvits and Goosmann (2016) Risikoledelse og krisestyring. [online] http://partneradvokater.dk/files/Dokumenter/Rapportrisikoledelse-og-krisestyring-i-SMV-2016.pdf (Accessed 03/03/19).

Tranchard, S. (2018) "The new ISO 31000 keeps risk management simple", ICO News, (May), pp. 180-183. Available at: https://www.iso.org/news/ref2263.html.

von Krogh, G. (2009) "Individualist and collectivist perspectives on knowledge in organizations", Journal of Strategic Information Systems, Vol. 18, No. 3, pp. 119-129. 